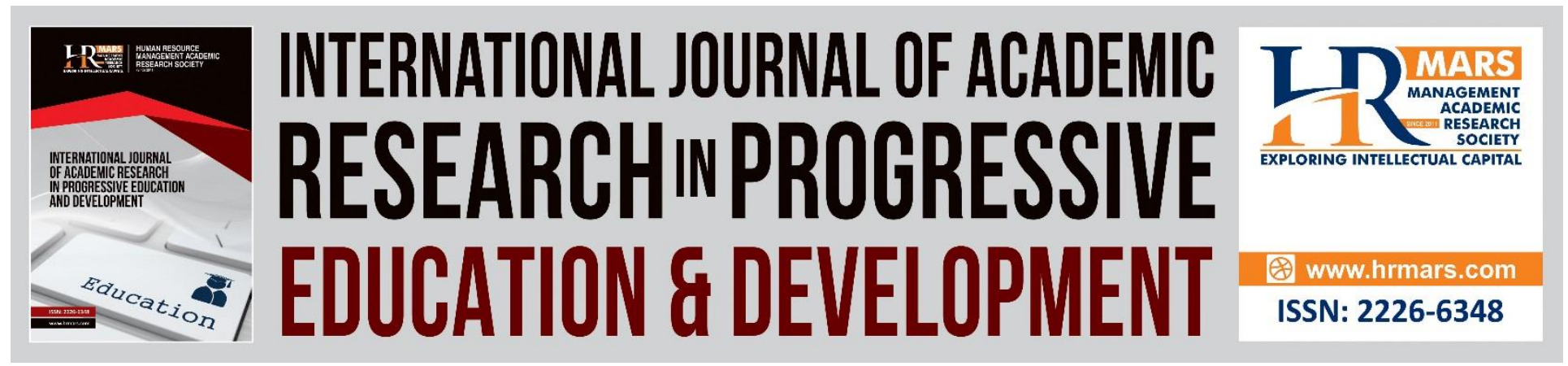

\title{
Digital Era: New Trends in Information Agencies
}

Saiful Farik Mat Yatin, Hamizaizurah Abd Hamid, Junaidah Rosliy Khuzaimah Mohd Shah, Zaiton Hassan

To Link this Article: http://dx.doi.org/10.6007/IJARPED/v7-i3/4355

DOI: $10.6007 /$ IJARPED/v7-i3/4355

Received: 05 June 2018, Revised: 18 June 2018, Accepted: 06 July 2018

Published Online: 23 July 2018

In-Text Citation: (Yatin, Hamid, Shah, \& Hassan, 2018)

To Cite this Article: Yatin, S. F. M., Hamid, H. A., Shah, J. R. K. M., \& Hassan, Z. (2018). Digital Era: New Trends in Information Agencies. International Journal of Academic Research in Progressive Education and Development, 7(3), 150-160.

\section{Copyright: (C) 2018 The Author(s)}

Published by Human Resource Management Academic Research Society (www.hrmars.com)

This article is published under the Creative Commons Attribution (CC BY 4.0) license. Anyone may reproduce, distribute, translate and create derivative works of this article (for both commercial and non-commercial purposes), subject to full attribution to the original publication and authors. The full terms of this license may be seen at: http://creativecommons.org/licences/by/4.0/legalcode

Vol. 7, No. 3, July 2018, Pg. 150 - 160

Full Terms \& Conditions of access and use can be found at http://hrmars.com/index.php/pages/detail/publication-ethics 


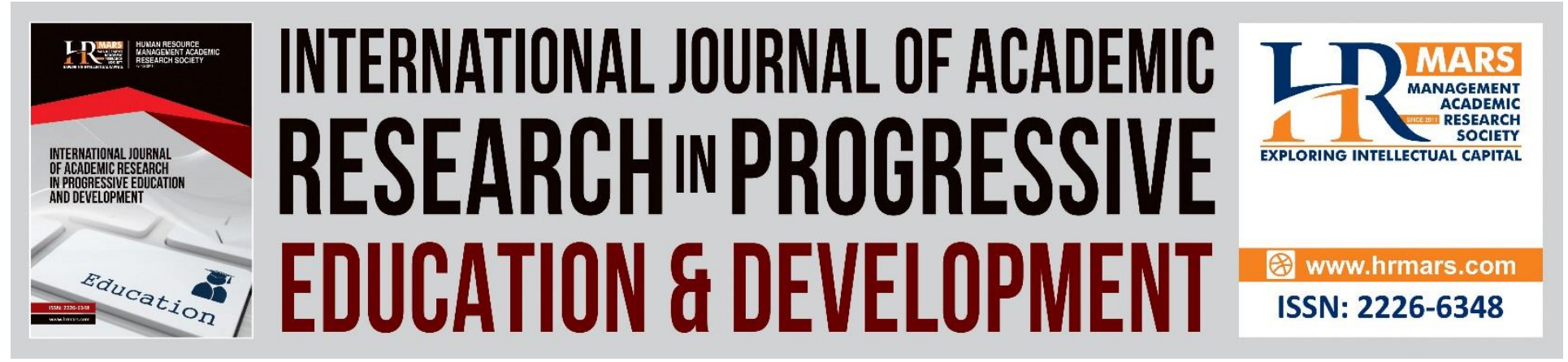

\title{
Digital Era: New Trends in Information Agencies
}

\author{
Saiful Farik Mat Yatin, Hamizaizurah Abd Hamid, Junaidah Rosliy \\ Khuzaimah Mohd Shah, Zaiton Hassan \\ Faculty of Information Management, Puncak Perdana Campus, UiTM Selangor, Malaysia \\ Email: farik@salam.uitm.edu.my,hamizaizurah.hamid@gmail.com
}

\begin{abstract}
The advancement of ICT (Information, Communication and Technology) in recent years has brought a lot of changes and improvement not only on the information agencies but also include the roles and expectations in the needs of digital information and knowledge. The purpose of this study is focuses new trends in information agencies and services in digital era. Several information agencies selected to study what new trends in digital era. Data center is the new information agencies that highlighted in this study. The major components of a data center are internet access, hosting, content of distribution, file for storage and backup and etc. This study also focuses the main issues and also the challenges in new era for information agencies. All information must be collected and preserved in information agencies as platform for references future generations. Technology is the important tools in information agencies because as collecting organizations they become more concerned with electronic information. The new era in information agencies will be an embodiment of a digital information professional or digital knowledge worker, to ensure that the digital information is to be used in effectively and with ease to users.
\end{abstract}

Keywords: Information Agencies, Digital Libraries, Virtual Museum, Electronic Archive, Record Centre, Information Management

\section{Introduction}

Recently, the growth for Information agencies users to getting all the information requested through online services, with free of charges and getting open access at all time. Throughout the use of online and digital offered to the users, it will help them to reach out the information easily without boundary. Together, with the combination of libraries, museums, records centre and archive, it will help them continue to expand their collections and services to become more available and accessible on the Internet for better reception. International Federation of Library Association (IFLA) Professional Committee at the IFLA World Library and Information Congress in Milan 2009, formulated the vision statement that 'to employ the fullest potential of digital technology in partnership with users by enabling seamless and open access to all types of information without limits to format or geography, and to enhance the ability of libraries, 
INTERNATIONAL JOURNAL OF ACADEMIC RESEARCH IN PROGRESSIVE EDUCATION AND DEVELOPMENT

Vol. 7, No. 3, July 2018, E-ISSN: 2226-6348 @ 2018 HRMARS

archives and museums to collaborate among themselves and with others to offer the broadest and most complete service possible'.

\section{Types Of Digital Information Agencies}

\section{Digital Libraries}

The rapid development of digital era has contributed to the transformation of traditional libraries toward digital libraries. Digital libraries can also be defined as virtual libraries, electronic libraries and libraries without walls.

Digital libraries play an important role in identifies the effectiveness of information repositories in order to support the need of information.

Md Anwarul Islam, Mitsuru Ikeda (2014) stated that digital libraries are increasingly developing worldwide because of its functionality that can be accessed everywhere at any time, access to information more widely, sharing information more easily, various of quality information, time savings, reduce human resources, new trends in information seeking and improve information security. Fulfill the need of modern societies, digital libraries are becoming the most important and influential institutions in each country.

\section{Virtual Museum}

Virtual museums have been defined as "multimedia products or web sites capable of providing new and fresh experiences of a specific museum and its heritage". Through the use of the web as a communication tool, it allows the museum to imitate display space, exhibits and tours, objects and at the same time able to increase access to the user and provide new experiences to them. By harnessing the functionality of the web, and in particular the "associative capabilities of hypertext" (Giaccardi, 2006), the museum experience can be enhanced and extended to include things which simply are not possible in the physical environment.

Through the virtual museum, it allows visitors to enjoy exhibitions from various environments at their own convenience as at home. Additionally, internet allows visitors to access to museum collections and referral databases. It also allows museums from various countries to connect more easily which is indirectly enhance communication among museum administrators, countries, and educational centers around the world.

Virtual museum is an idea that uses a website display containing artifacts for public viewing. Otherwise it also allows users to feel the same space as the real museum. Virtual museum also allows individuals to enjoy visual museums without having to leave their home. This also benefits the disabled person with no physical or limited access to the museum. Virtual museum also allows users to plan their visit and it is up to them whether to focus on the areas they are interested in or expedites their visit.

\section{Commercial Record Center}

The record center is a place and an organization that can collect, store and manage all records such as documents for finance, law and business. The center of records will usually manage and support the whole process of record-keeping life cycle, from records collection through records management to records of disposal. This life cycle includes identifying, classifying, storing, securing, retrieving, detecting and destroying or retaining records permanently. 
Vol. 7, No. 3, July 2018, E-ISSN: 2226-6348 @ 2018 HRMARS

Commercial record centers (CRC) are facilities and services which provide for the storage for paper records for organizations. They also offer storage for records maintained in electronic formats like CDROM, AV Materials and etc. Some organization offer average temperature controlled storage for sensitive non-paper and vital paper media.

Commercial records center has evolved from what began as a repository of mostly inactive, records into a much more interactive, high technology relationship with its client. With latest technologies, CRC now offer very sophisticated computer-based indexing, disaster recovery and etc.

\section{Digital Archive}

Digital Archive is a center and place which is to stores and manage the content of electronic and digital information according to its segment and their characteristics. The purpose of implementing the management of electronic digital archive is to ensure the availability and accessibility of that information for long term access. The growth of vast Information Technology systems and network help people to store and keep the information for a very long time. It is also ensure that all important moments can be captured and stored for the human society. In addition, it can assist to store and preserved the valuable contents of national socio-cultural and heritage from the past.

The process of digital archive consists of identifying, appraising, labeling and coding, and preserving the lifecycle of that records which can be obtained in online and electronic formats. This process, together the implementation of structured guidelines, policies and integrated systems, will allow the availability of that this digital record and object can be maintained throughout the time.

Electronic information makes it possible to use information for many different purposes, more than has ever been possible before. Nowadays, as digital technologies rapidly replace the conventional, the conditions of archiving presence are once again changing drastically.

\section{New Trends In Information Agencies}

Authorities should be aware that active planning for information agencies in 21 century at any level (national, regional and local) should cover the following issues:

\section{Knowledge Management in Digital Libraries}

Nowadays, libraries facing various challenging with the the unpleasant effects of the digital age. It is important for each library to find out the most creative and innovative solution to maintain continuity and remain relevant for the nation in twenty first century who has the knowledge, skill, ability and desire in finding vast amounts of information in just a minute without come or spend so much time in the library. Knowledge has been recognized as the ultimate resource of information of our days. From this perspective, digital libraries responsible to provide an extraordinary platform to fulfill their role towards a first class society based on knowledge and learning.

Md Anwarul Islam and Mitsuru Ikeda, (2014) mention that digital libraries and knowledge management have a close relationship to each other. The application of theories and methods of knowledge management in building digital libraries can develop the quality and strengthen of 


\section{INTERNATIONAL JOURNAL OF ACADEMIC RESEARCH IN PROGRESSIVE EDUCATION AND}

DEVELOPMENT

Vol. 7, No. 3, July 2018, E-ISSN: 2226-6348 @ 2018 HRMARS

their service, improve in managing knowledge management in digital libraries methods and sustain adaptability in a frequently changing of digital environment. Evolution in the development of digital libraries are necessary for knowledge society in order to support the process of capturing, sharing and transferring valuable knowledge that can be use as an important asset for the organization successfulness.

Issues on how professional librarian could get benefit using knowledge management features in their digital libraries development and enhance a greater understanding of knowledge management in digital libraries in general has been identify. Based on the research result, professional librarians mostly know about knowledge management and feel interested in applying knowledge management in their digital libraries because of various factors as below:

- Improve quality of services in digital libraries

- Create knowledge transfer and knowledge sharing culture among stakeholder

- Support daily operation of the digital library through storytelling (share tacit knowledge), training (online and off line course, education) and mentoring session (ability to motivate, remain professional approach)

\section{KM-based digital library system}

Md Anwarul Islam and Mitsuru Ikeda, (2014) state that service-based knowledge management system in digital libraries is systematically designed according based on several step. The process need start from acquiring relevant knowledge and capture what they have knowledge in organization to create new knowledge. All knowledge already processes need to storage and easy to retrieval in proper way also easy access. Lastly, disseminate knowledge to people for sharing, apply, utilize and using for organization.

\begin{tabular}{|c|c|}
\hline \multicolumn{2}{|r|}{ Overview KM-Based Digital Library System } \\
\hline System & Function \\
\hline $\begin{array}{l}\text { Digital knowledge } \\
\text { acquisition } \\
\text { system }\end{array}$ & $\begin{array}{l}\text { Capture and process digital information resources and the conversion of } \\
\text { information into knowledge }\end{array}$ \\
\hline $\begin{array}{l}\text { Knowledge } \\
\text { organization and } \\
\text { processing system }\end{array}$ & $\begin{array}{l}\text { Organize, manage and retrieve information and knowledge through } \\
\text { intelligent classification and matching operation of collected knowledge } \\
\text { and existing knowledge }\end{array}$ \\
\hline $\begin{array}{l}\text { Knowledge base } \\
\text { storage and } \\
\text { retrieval system }\end{array}$ & $\begin{array}{l}\text { Develop knowledge through KM tools (taxonomies, knowledge mapping, } \\
\text { data mining and metadata) }\end{array}$ \\
\hline $\begin{array}{l}\text { Dissemination of } \\
\text { knowledge }\end{array}$ & $\begin{array}{l}\text { Transfer and sharing information and knowledge from one person to } \\
\text { another }\end{array}$ \\
\hline
\end{tabular}

Therefore, it is expected that implementation of KM-based digital library system offer a number of benefits for the stakeholders and these are: 
INTERNATIONAL JOURNAL OF ACADEMIC RESEARCH IN PROGRESSIVE EDUCATION AND DEVELOPMENT

Vol. 7, No. 3, July 2018, E-ISSN: 2226-6348 @ 2018 HRMARS

- Strategic planning in decision making for executive strategies, information knowledge resource allocation and analysis strengths, weakness, opportunities and threats for the improvement of digital library system and services.

- Developing a knowledge-based culture between users and digital libraries

- Improve job quality because the stakeholder can work in environment that offer free flow of ideas

- Enhance organizational performance, innovation and development through the acquisition, sharing and management of information and content in various formats that can be useful by the society

- Create innovation in digital libraries services by collecting users' needs and satisfaction through periodic users' surveys and findings

\section{Virtual Exhibition}

Museum exhibits are synonymous with conventional ways in which they prefer to place real objects with limited explanations written by curators on panels next to objects or through audio devices used during visits by personal tutors. However, such techniques have many negative aspects, such as the presence of distance between visitors and artifacts, not educating and making visitors feel isolated because they do not have the opportunity to communicate with each other about objects or artifacts that interest them. Therefore, museum exhibitions should allow visitors to interact with real objects. Furthermore, the museum should be a "multi-dimensional educational institution" where the visitor can get the information and additional resources of the artworks for their references.

The exhibition in virtual museum is a digital representation of the artifact. It consist various multimedia formats that can be placed inside the virtual gallery such as text, images, 3D models and videos. In order to make the virtual museum more lively for the user, some techniques can be used such as the Virtual Reality (VR) or Augmented Reality (AR) to enrich and enhance the component of the interactive virtual museum exhibition. Augmented reality $(A R)$ is the extension of VR system that can be mixed for real-time interaction. Using standard Virtual Reality Modeling Language (VRML) browsers, the spaces can be visualized, interacted with and explored by the visitors. With many interactions that the system have been provided, the visitor of the museum web can participate in quizzes about the exhibits; examine the exhibits in VR environments from different perspectives; freely observe the exhibits in indoor AR environments and finally the visitor will have a chance to interact with the artifacts replica through safe multimodal interface. The implementation of AR indirectly may fill the gap between traditional museums that lack in offering enough interactive exhibitions for visitors.

With the usage of AR techniques and VR interfaces, the virtual museums exhibitions have a lot to offer compare with many current museum web sites nowadays. It also offer many advantages for museum visitors such as interaction devices that can be integrated into multi-modal augmented and virtual reality interactive interfaces. Furthermore with this technology enable the museum to build an interesting interactive exhibition for the visitor such as museum kiosk. The kiosk can be simple as a PC desktop system and not the expensive one. Standard PCs with cheap interfaces can be modified by replacing repository content for new virtual tours. 


\section{Electronic Record Keeping System}

Electronic recordkeeping systems are an electronic recordkeeping system and they must meet the requirements by National Archives and Records Administration (NARA). The function of this system is to able to collect, organize, and categorize records. It does also can facilitate and manage the preservation, retrieval, use, and disposition of records. Wei Mei Pan (2017) opines that this project is to investigate the socio-technical surrounding users' interaction with electronic recordkeeping systems.

In order to improve the interaction by user, implementation of systems must be in placed to gain better understanding factors and process to contribute success. An electronic recordkeeping system (ERKS) is an electronic information system (IS) that meets an agencies' recordkeeping needs (USA National Archives and Records Administration, 2000). Requirements, standards and specifications have been developed by records management and archival practitioners and scholars to assist the design and development of ERKS.

Implementation of an IT system has been defined as "an organizational effort directed toward diffusing appropriate information technology within user community" (Cooper and Zmud, 1990). The implementation of ERKS are the process to descriptive which is relating the authors' experience to managing an ERKS implementation project and also for discussing a number of factors to perceived as significant in influencing the success of the project.

Analysis of interview data identified some of key themes in implementation ERKS. These themes are:

- The value that accorded to information and records

- The process is a complex for implementation of electronic recordkeeping system

- Appropriately of the electronic recordkeeping systems

- Understanding users

- Ease of use

- Involvement by users in the development and implementation of the system

- A part of the solution is the involvement by information or records specialists

\section{Electronic Records Archives}

Previously, before the era of digitization of managing the records and information, people tend to store everything in physical form, which contains all the information being stored without having the classification. As a result, it generated challenges for the society on how to properly organize and manage the problems and issues arise from the real-situation occurred during those times. Today, with the emergence of electronic and digital record archive concept, it has become the current and most convenient way of keeping the record practically and systematically. As the rapid growth in today's society, there are massive increasing amount of information and record being created and store in electronic digital medium or format. All the valuable and important records can be stored online, which offers the society with various amounts of great benefits electronically.

In order to in line with the benefits of having digital record and archive, the importance of digital archiving processes must be controlled and maintained from the early beginning of creation and used of process cycle until the dissemination of information to the end user. The system must be 
Vol. 7, No. 3, July 2018, E-ISSN: 2226-6348 ๑ 2018 HRMARS

able to support various range of records and archive requirements according to the nature of the organization. This will help the society to access the records archive in the form of electronic and computerized easily.

One of the most well-known electronic records archives management being referred globally is ERA. Electronic Records Archives (ERA) is the National Archives and Records Administration's (NARA) developed system that allows an organization to store and manage the records activities with NARA through online systematically. This was designed to preserve and manage NARA's electronic information or records and to manage the lifecycle of records and other required objects or information, which is including assist for records maintenance lists and the accessibility activities for all records.

\section{Data Centre}

Data Centre is a repository for storage and manage that houses computing facilities like servers, routers, switches and firewalls, as well as supporting components like backup equipment, fire suppression facilities and air conditioning. A data center can be complex (dedicated in building) or can be simple (an area or room that houses only a few servers). Data center also can be private or shared with others.

A data center needs to equipped with a guaranteed power supply and high bandwidth connectivity. It is because the resilience is critical so redundancy (duplication) of networks, power and other infrastructure is common to ensure continuity. Other facilities include the building management controls such as air conditioning for maintaining the environmental conditions for the equipment in data center within a specified envelope of temperature and humidity also needs security systems to ensure that the facility and its data remain secure.

The major components of a data center are internet access, hosting, content of distribution, file for storage and backup, database management, failsafe power adequate heating, ventilation and air conditioning (HVAC) and fire suppression,

high-performance cabling infrastructure and high technology of security system like access control, video surveillance.

\section{Malaysia Data Center Project}

Malaysia's Data Centre \& Cloud industry is vital project to broad trends of expansion, efficiency, and consolidation. Malaysia Digital Economy Corporation (MDEC) is in charge this project to position Malaysia as a regional hub for data centre and cloud services by leveraging and expending on various factors such as cost efficiency, availability of skilled workers, and a strong foundation of data governance laws. The list of main projects as below:

\section{a. ALIBABA Cloud}

First global public cloud platform in Malaysia that offer a comprehensive suite of cloud products and services ranging from elastic computing, database service, networking, security, middleware, to analytics and big data. Digital News Asia mention that this is first digital hub under the Electronic World Trade Platform (eWTP) initiative and play a key role in incubating startups of Malaysia as well as across ASEAN countries. 
INTERNATIONAL JOURNAL OF ACADEMIC RESEARCH IN PROGRESSIVE EDUCATION AND DEVELOPMENT

Vol. 7, No. 3, July 2018, E-ISSN: 2226-6348 @ 2018 HRMARS

\section{B. Cyberjaya3 Data Center}

Cyberjaya3 is a 3-story data center block with 30,000 square feet of space which offers the customers a tier 3 ready for environmental friendly data center. It was built to deliver architectural scalability, resilience and unparalleled power consumption. This offers to enhanced data security, high-performance technology, extra low latency and extrareliable services.

\section{Aims}

Leading for provider of premium carrier neutral data centre and also to manage services and host to all domestic and more than 80 percent of foreign telecommunication carriers based in malaysia.

\section{Issues and Challenges in Information Agencies}

Management

For the provision of world class information and knowledge creator, resources and services in information agencies need the wholehearted support from the respective management. Rational division of labor in information agencies needs to be implemented to enhance the main function; and cooperation and coordination are necessary in order to achieve co-building, sharing and coprosperity of interlibrary knowledge information resources.

\section{Funding}

New technologies in information agencies required big allocation and monetary funding from respective parties. Information agencies are generally considered to be more sensitive to changes in financial conditions. External funding tends to be relatively more expensive for them because providers of finance have less information about their creditworthiness.

\section{Technology}

Requirement of high technologies is required for successfulness of implementing information agencies in 21 century. Tools (IT based) play an important role in information and knowledge discovery organization and sharing in an organization.

\section{Expertise}

Human factors are also given priority in designing, developing, organizing, managing, maintaining, and operating information agencies in the 21st century. Experience and expertise refer to knowledge, skills, competencies and capabilities of information professional and other human resources to deal with digital resources, technologies, system designs and service promotion.

\section{Conclusion}

Information Agencies play a fundamental role in our society. They are the collectors of national heritage and knowledge needs, they are also are organizers of the valuable knowledge, history and learning process. Information Agencies take the knowledge of the past and the present, and it lay down for the future used. 
INTERNATIONAL JOURNAL OF ACADEMIC RESEARCH IN PROGRESSIVE EDUCATION AND DEVELOPMENT

Vol. 7, No. 3, July 2018, E-ISSN: 2226-6348 @ 2018 HRMARS

Information Agencies face real challenges in implementing their role with the rapid transition to the digital era. To maintain continuity and avoid becoming the burden of the future, information agencies are necessary to deep changes in the organizations including services, facilities and human resources in term of skills, attitude and expertise. Information Agencies also have a unique role in disseminating knowledge for collections and services innovation.

Those agencies developed in performance with their local and national history. Political, economic and social circumstances create, shape and develop the importance of Information Agencies. Among those agencies, we can find diversity and difference. The most modern and well-equipped library is not necessarily the most developed in the art of stimulating popular participation and democracy. Good examples can be found all over the world.All Information agencies were set up with their own roles and objectives, background and standard of

arrangements, but among those agencies, they were bounded with the same mission and attention in nurturing knowledgeable society and promotes long life learning.

\section{References}

Anixter (2012). Data Center Infrastructure Resource Guide. Retrieved December 3, 2017 from https://www.anixter.com/content/dam/Anixter/Guide/12H0013X00-Data-CenterResource-Guide-EN-US.pdf

Blyth, T. (2016). Exhibiting information: developing the Information Age Gallery at the Science Museum. Information \& culture, 1-28. doi:10.1353/lac.2016.0001

Donghee Sinn, Sujin Kim \& Sue Yeon Syn, (2017). Personal digital archiving: influencing factors and challenges to practices. Library Hi Tech, 35(2), 222-239. doi:10.1108/LHT-09-20160103

Giaccardi, E. (2006). Collective Storytelling and Social Creativity in the Virtual Museum: A Case Study. Design issues, 22, 29-41.doi:10.1162/desi.2006.22.3.29.

IFLA. (2014), About digital libraries. Retrieved December 3, 2017 from https://www.ifla.org/about-digital-libraries

MDEC. Data Center (2017). Retrieved December 2, 2017 from https://www.mdec.my/digitalinnovation-ecosystem/data-centre-cloud.

Islam, M. A. \& Ikeda, M. (2014). Convergence issues of knowledge management in digital libraries: steps towards state-of-the-art digital libraries. The journal of information and knowledge management systems, 44(1), 140-159.doi:10.1108/VINE-05-2013-0029

Person, D.A., \& Plumb, T.K. (2017). Digital archives from the ground up. Digital Library Perspectives, 33(3), 253-263. Retrieved December 15, 2017, from https://www.archives.gov/files/records-mgmt/pdf/what-is-era.pdf. 
INTERNATIONAL JOURNAL OF ACADEMIC RESEARCH IN PROGRESSIVE EDUCATION AND

DEVELOPMENT

Vol. 7, No. 3, July 2018, E-ISSN: 2226-6348 @ 2018 HRMARS

Techopedia (2017). Data Center. Retrieved December 3, 2017 from

https://www.techopedia.com/definition/349/data-center

Weimei Pan. (2017). The implementation of electronic recordkeeping systems: an exploratory study of socio-technical issues. Records Management Journal, 27(1), 84-

98.doi:10.1108/RMJ-04-2016-0014

Yu-Chang Li, A.W.-C. (2012). The digital museum: challenges and solution. $20128^{\text {th }}$ International Conference on Information Science and Digital Content Technology (ICIDT), 646 - 649.

Retrieved December 2, 2017 from

http://ieeexplore.ieee.org.ezaccess.library.uitm.edu.my/xpls/icp.jsp?arnumber=6269353 